\title{
El Leviatán como aparato de captura: una perspectiva materialista sobre la forma Estado desde Marx, Althusser, Foucault y Deleuze ${ }^{1}$
}

\author{
The Leviathan as a capturing apparatus: a materialist \\ perspective about State form from Marx, Althusser, Foucault \\ and Deleuze
}

Israel Arcos·chuck_biri@hotmail.com

UNIVERSIDAD DEL PAÍS VASCO/EUSKAL HERRIKO UNIBERTSITATEA

Recibido: 03-04-2016

Aceptado: 25-05-2016

\section{Resumen}

Este artículo trata de establecer un abordaje de la naturaleza estatal desde una concepción materialista asentada en autores como Marx, Althusser, Deleuze o Foucault, que frente a cualquier misticismo o ideología sobre la forma Estado, como por desgracia han caído en muchas ocasiones las distintas teorías del Estado, anclan la problemática del Estado desde unos análisis apegados a las prácticas estatales y su materialidad. En este sentido, se tratará de buscar una definición del Estado, la razón de su existencia, una última naturaleza si la tuviera, sobre todo, si tenemos en cuenta, la confusión que supone la multiplicidad de formas de adjetivarlo que surgen en estos tiempos posmodernos.

Palabras clave: Estado, Capitalismo, Deleuze, Althusser, Marx

\section{Abstract}

This article seeks to establish an approach to the nature of the State from a materialistic conception established in authors like Marx , Althusser, Deleuze or Foucault, in opposition to any mysticism or ideology about the State form, that unfortunately in many occasions the different theories of the State have fallen, anchoring the problematic of the State from some analysis attached to State practices and its materiality. In this regard, it will try to seek a definition of State, the reason for its existence, an ultimate nature if it has, especially if we consider the confusion that implies the multiplicity of ways to refer to it, that arise in these postmodern times.

Key words: State, Capitalism, Deleuze, Althusser, Marx 


\section{INTRODUCCIÓN}

No es fácil definir el concepto Estado en los tiempos que corren. Allí donde miramos y buscamos explicaciones, éstas se prolongan en un mar de confusiones; siempre que irrumpe la palabra Estado, le acompaña un adjetivo, en ocasiones valorativo, que intenta describir su naturaleza en época posmoderna: Estado mercado, Estado mínimo neoliberal, Estado posmoderno, Estado red (Castells), Estado competitivo schumpeteriano (Jessop), Estado transnacional (Beck)... demostrándonos, que si en definitiva, en otros tiempos, existía un consenso a la hora de definir la naturaleza estatal, en la era de la subsunción real (Marx, 1971: 55-77)² la comprensión del Estado se hace una tarea dificultosa. Quizás, porque decir Estado, en la actualidad, sea decir nada; o con otras palabras, que la forma Estado es eso, una forma: mutable, cambiante, cuya definición jamás estará cerrada. Pero a pesar de ello, que sea flexible, que pueda cambiar su nombre, que las características que le definen sean distintas en distintos períodos, no implica que no tenga una esencia, una última lectura, pues sino no existirían ni sus posicionamientos a favor o en contra. Si hay algo que define al Estado, desde los análisis que nos brindarán los autores de los que nos serviremos, es su condición de dominio, su colaboración siempre con el poder, su manera de tratar de controlar los distintos flujos, subjetividades, líneas de fuga, en el territorio que es de su dominio. Por ello, muchos de los autores que señalaremos, rechazaron la forma Estado: en su forma realmente existente y en su experiencia histórica, que no supone rechazar de ningún modo la aspiración a una forma de institucionalidad democrática nueva.

Una primera huella de la refutación estatal la encontraremos en Marx, a pesar de las derivas en pro de cierta estatalidad de algunos de sus seguidores. Como bien señaló Noberto Bobbio, en forma de crítica al marxismo, Marx y sus seguidores no poseían una teoría sobre el Estado33. Claro está que Marx no escribió nada que sería una especie de teoría del Estado, pero eso es porque la única teoría que Marx podía tener en la cabeza era la de la destrucción del dispositivo estatal ${ }^{4}$. Esa es nuestra hipótesis sobre la enseñanza de Marx: en su silencio sobre el Estado, el mensaje clarividente y rotundo de que no hay democracia en la forma Estado $^{5}$. Por ello, pensar el Estado, desde una óptica materialista vía marxiana, es pensar su rechazo. En todo caso, si es posible una teoría del Estado marxista, sería una crítica de la

\footnotetext{
${ }^{2}$ Para la comprensión de la fase actual en la que nos vemos inmersos vaticinada por Marx, véase la cita bibliográfica señalada. En síntesis, podríamos decir, que el estado de la subsunción real es esa fase en la que el capitalismo se ha hecho materialmente constituyente gracias al desarrollo de la industria, los avances tecnológicos y de la ciencia; donde ya, verdaderamente, resulta difícil encontrar resquicios libres a la forma mercancía.

${ }^{3}$ En la década de los 70 hubo en Italia un debate muy conocido entre Noberto Bobbio y algunos marxistas italianos (Bobbio, 1977), en el que Bobbio argumentaba que en la obra de Marx era imposible localizar una teoría general del Estado. Los marxistas contestaron que eso no era del todo cierto ya que en Marx existía un germen de una teoría general del Estado que más adelante desarrollarían otros autores deudores de Marx. Pero en honor a la verdad, era Bobbio quien tenía razón como señalaremos.

${ }^{4}$ Sabemos que Marx tenía pensado escribir un libro sobre el Estado en la redacción previa de Das Kapital que al final no realizaría. Si aceptamos las tesis de Román Roldozski (Roldozski, 2004: 39) por la cual los Grundrisse son la antesala del Capital, es decir, una especie de borradores de lo que sería al final la redacción de su obra cumbre frente a las tesis de Negri que los considera como unos textos que mantienen importantes diferencias con Das Kapital (Negri, 2001), Marx tendría una estructura de la obra que incluía un libro IV titulado sobre el Estado en los borradores de 1857 que desaparece en el boceto de 1866.En definitiva, Marx eliminaría el libro sobre el Estado ya en los borradores de 1865; en el resto de su obra, las alusiones al Estado están dispersadas por toda su obra sin constituir ninguna teoría general del Estado.
} 
forma Estado, nunca, y esto hay que dejarlo claro, una legitimación del dispositivo estatal; de la necesidad del Estado, ya sea como horizonte utópico o como presente en las necesidades del realismo político, ya están otros por muy marxistas que se consideren, pero desde luego, no Marx. Desde nuestra lectura del texto marxiano, el marxismo, el marxismo de Marx y no de otros, es la crítica al Estado; el Estado es insalvable. Todo esto sonará raro: “¿pensar la disolución del Estado?”... “¿y es esa la herencia de Marx?”, esto lo pensarán muchos y les extrañará; los mismos que ven el mundo en dualidades firmes que lo confunden todo. Parecen ignorar que la dualidad mercado-Estado es falsa, que no es que sea el Estado el cielo y el mercado el infierno, sino que ambos son lo mismo, y esto no es una banalidad ni una indiferenciación de los conceptos, por el contrario, decimos que el Estado sirve al mercado y que si ahora su poder se ve mermado es porque interesa al nuevo modelo financiero, al capital, que esto sea así, como en otros tiempos pudo interesar lo contrario. Las mejoras que haya podido reportar tal maquinaria a la multitud, no derivan de una voluntad benévola del Estado sino de las necesidades del poder ${ }^{6}$, y a lo sumo, como mucho, de las demandas democratizadoras de las formas de vida que éste siempre sabe canalizar.

De esta manera, nuestro análisis recogerá el espíritu marxiano de estudio del Estado como crítica, pero también, de Michel Foucault, y sobre todo, de Gilles Deleuze ${ }^{7}$ : del primero nos inspiraremos en su enfoque sobre las prácticas estatales en vez de buscar una esencia que lo defina; el segundo nos permitirá ver al Estado desde un prisma que le sitúa como ese dispositivo regulador y canalizador de las subjetividades que intentan escapar al dominio. Sin duda alguna metodología materialista que atiende al ser del Estado y no al deber ser, por utilizar una diferenciación kantiana, o mejor dicho, que el Estado es lo que es y no cabe pensar en un Estado ideal, porque ya no sería un Estado sino otra cosa. En todo caso, el objeto de estudio del deber ser del Estado sería el de la teoría del Estado; ensoñaciones utópicas que en muchos casos legitiman al poder. Sólo el estudio de la materialidad de las prácticas estatales nos dará una definición de lo que verdaderamente es la forma Estado.

${ }^{5}$ Es importante aclarar que por democracia entendemos una democracia absoluta de espíritu spinoziano, es decir, aquella forma gubernamental de vivir juntos de manera armónica donde las singularidades libres e iguales pueden alcanzar al máximo sus potencialidades sin perjudicar ni excluir al "otro" mediante la existencia de una nueva institucionalidad que no las constriña; algo que vaya más allá de la institucionalidad de carácter público ( forma Estado tal como la conocemos) y de corte privado ( el mercado de carácter capitalista), y que vendría a ser la institución del común.

${ }^{6}$ El Estado sirvió para la creación del mercado nacional en la modernidad, también contribuyó a la expansión de los mercados mediante el imperialismo, incluso el famoso Welfare state fue más una respuesta a las crisis de sobreproducción vía Keynesianismo que una voluntad benefactora del Estado resultado de las demandas ciudadanas. Incluso, en los últimos tiempos, el Estado colabora con su estrechamiento y su mutación hacia un Estado mínimo, es decir, realiza un intervencionismo a la inversa( no interviniendo tanto en la vida social, que también es una forma de intervenir).

${ }^{7}$ Para algunos marxistas, parece que Deleuze y sus concepciones del poder no les resultan para nada herederas del pensamiento materialista de Marx. Tal es el caso, por ejemplo, de Nicos Poulantzas que enfrenta a Deleuze con el marxismo, como si fuesen pensamientos antagónicos. El primero frío y analítico, mientras que el segundo sería unas especie de teoría espiritualista y críptica. Desde luego no compartimos las posiciones de Poulantzas sobre Deleuze. Sin duda alguna, Deleuze pertenece a esa rama del pensamiento que podemos denominar materialismo, y que de Lucrecio pasando por Spinoza o Marx llega hasta Foucault o el mismo Deleuze. El propio Deleuze, en sus últimos años de vida, tenía pensado escribir un ensayo sobre Marx titulado la grandeza de Marx, que no vio nunca la luz por su suicidio. Siendo un lector atento, uno puede encontrar la impronta del espíritu de Marx que recorre algunos de los capítulos de esa gran obra llamada capitalismo y esquizofrenia; sobre todo los capítulos relacionados con el funcionamiento del capitalismo. Sobre las posiciones en contra de Deleuze véase (Poulantzas, 1979: 17). 
De tal forma trataremos de responder a una serie de interrogantes de manera muy sintética en este artículo: ¿qué es el Estado y cuáles son sus prácticas?, ¿tiene alguna naturaleza o esencia última que lo defina?

\section{TEORÍAS SOBRE LA NATURALEZA DE LA FORMA ESTADO; UNA BREVE EXPLORACIÓN}

En primer lugar, formalmente, es lugar común definir al Estado bajo tres premisas: 1) "el Estado es un conjunto de instituciones; estas instituciones son gestionadas por el propio personal del Estado.” (Hall e Ikenberry, 1993: 10); 2)“estas instituciones están enmarcadas en un territorio geográficamente delimitado, al que generalmente se denomina sociedad.” (Hall e Ikenberry, 1993: 10); 3) "el Estado monopoliza el establecimiento de normas dentro de su territorio" (Hall e Ikenberry, 1993: 11). Sin duda alguna, como reconocen los autores de este tipo de definiciones, esta definición es de raíz weberiana (Weber, 1993). A pesar de no negar la valía de esta definición, nos parece que es bastante pobre, ya que en su obviedad no dice nada, además de que en la actualidad, con lo que se ha venido denominando la crisis del Estado en la era de la globalización, los tres puntos mencionados como definitorios pueden considerarse puestos en cuestión ${ }^{8}$.

Esta visión que mantiene Weber en Economía y sociedad, inaugura según muchos, un enfoque del Estado que se independiza del derecho público (algo que no es cierto del todo pues ya Marx había analizado antes que Weber el dispositivo Estatal desde un análisis totalmente alejado de las visiones idealistas filosóficas (Hegel, etc.) y las jurídicas, lo único que sin fundar ninguna nueva ciencia del Estado o enfoque de escuela; recordemos que Marx no quería realizar ninguna teoría del Estado) para crear un análisis sociológico del Estado. Según Webber hay que hacer una distinción entre un "enfoque jurídico” que sería la validez ideal y un "enfoque sociológico” que sería la validez empírica. Esto no es más, que la distinción que anteriormente había realizado Georg Jellineck entre doctrina social del Estado y doctrina jurídica del Estado; la primera se fundamenta en la existencia objetiva e histórica del Estado, mientras que la segunda se inscribe en el estudio de las normas jurídicas que en el Estado se expresen (Jellinek, 2012). Es importante recordar esta distinción, porque otras definiciones minoritarias del Estado niegan esta división para abordar su estudio. El ejemplo más clarividente al respecto es el de Hans Kelsen. El jurista alemán niega lo que él denomina la teoría dual de Jellinek, ya que el Estado se disuelve exclusivamente en el ordenamiento jurídico; es decir, una entidad fundamentada solo en la producción y ejecución de normas (Kelsen, 2008). Una teoría pura; un positivismo jurídico que acaba siendo verdaderamente pobre. El Estado es solo ese terreno de aplicabilidad jurídica, el Estado es el derecho y el derecho es el Estado, no hay más; la institución que dota de personalidad jurídica al pueblo.

\footnotetext{
${ }^{8}$ El Estado ni ya es gestionado en su totalidad por personal estatal, ni tiene la capacidad de reproducción de unas sociedades cada vez más heterogéneas en términos de nacionalidad, ni tampoco es el único que establece normas en su supuesta jurisdicción territorial, como nos muestran la pérdida de soberanía y lo que se ha denominado la gobernanza.
} 
En esta línea kelseniana podemos encontrar al que en su día fue maestro de un jovencísimo Antonio Negri, Constantino Mortati. El Estado, para Mortati, es simplemente un ordenamiento jurídico para lograr los objetivos generales que realiza el poder soberano en un territorio al que están subordinados los individuos que pertenecen a él (Mortati, 1969). Aquí el Estado se identifica con sus elementos clásicos modernos definitorios (un territorio, un pueblo, la soberanía), eso sí, siempre bajo la premisa inamovible de vincular al Estado con el ordenamiento jurídico. El poder en la visión kelseniana, identificada con el Estado, es meramente la capacidad de fundar y aplicar derecho.

Estas teorías de la órbita del mundo jurídico sobre el Estado, aún así, hacen diferencias en torno a la naturaleza del Estado; el elemento definitorio fundamental que es el del ordenamiento jurídico, no implica una indistinción de las formas Estado (el Estado es una forma que puede presentarse en distintas formas). Kelsen escapa de la banalidad, de la indiferencia, haciendo una distinción entre los Estados que fundan sus ordenamientos jurídicos de arriba abajo y los que lo hacen de abajo arriba; lo que en la ciencia política clásica sería el concepto de legitimidad del Estado en base a la diferencia entre Estados democráticos y Estados no democráticos. Giannini, por ejemplo, en base a la tradición de los juristas italianos de posguerra divide sin salir de la órbita kelseniana del Estado a éste en dos tipos principales: el Estado monoclase, que fundamentalmente es el Estado liberal, donde solo se ven representados los intereses de la burguesía; y por otra parte, el Estado pluriclase, es decir, el Estado democrático que representa los intereses de todas las clases ${ }^{9}$. Más adelante, esta tradición del derecho público italiano, se verá como mera ficción o farsa, al demostrarse, por ejemplo, que en Italia, el Estado social, el Estado pluriclase teorizado por Giannini, fundado en el trabajo, no fue más que un instrumento para obtener a través del consensualismo entre clases la empresa de poner a toda la sociedad en su conjunto a trabajar para el proyecto del desarrollo capitalista (Negri, 2003).

Retomando la distinción weberiana (enfoque jurídico y enfoque sociológico) o de Jellinek (doctrina jurídica del Estado y doctrina social del Estado), al fin y a la postre es la misma, podemos ver como al partir de los años 60 empieza a ser dominante ya el enfoque sociológico. A su vez, en este enfoque sociológico, podemos distinguir dos corrientes sin ánimo de ser excesivamente exhaustivos: por una parte la del funcionalismo y la del sistemismo en ciencia política, y por otra, la del marxismo (de raigambre estructuralista en gran medida).

El funcionalismo siendo muy sintéticos (no se trata de hacer una exposición demasiado extensa aquí), fundamenta la visión del Estado como un subsistema social que debe garantizar el equilibrio social junto a los otros tres subsistemas sociales (estamos hablando de la visión parsoniana, dejamos de lado la versión deudora de éste y renovada que es la de Luhmann). El Estado aquí, no es más que un conservador del sistema, del status quo; un dispositivo equilibrador de la vida social. La otra visión dominante dentro de este mismo enfoque, es el sistemismo behavioralista, muy deudor del funcionalismo. El Estado en esta corriente,

${ }^{9}$ Para un acercamiento sintético del concepto de Estado pluriclase en Giannini al albor de la crisis del constitucionalismo en la era de la globalización véase ( Maestro, 2001: 156-157). 
donde David Easton es el máximo exponente, simboliza un sistema donde recibe demandas (inputs) que salen en forma de políticas públicas u otras formas (outputs) que intentan satisfacer esas demandas, retroalimentándose el sistema de esta manera. A diferencia de las teorías funcionalistas, el sistemismo permite el cambio gradual de las sociedades, pero también puede implosionarse el sistema cuando éste no puede canalizar las demandas (Easton, 2013).

Frente a los enfoques sistémicos y funcionalistas, nos encontraríamos la visión de cierto marxismo continental de corte académico. Estamos hablando de autores como Poulantzas, Althusser (no estaría bien del todo situarlo aquí), Miliband, Offe, etc. Esta variante del marxismo, apelando al 18 brumario de Luis Bonaparte, donde Marx afirma que el Estado puede lograr cierta autonomía en relación a las rivalidades entre las distintas fracciones de la clase dominante, empieza a ver al Estado no solo como un dispositivo al servicio de ésta (visión del manifiesto comunista) sino algo más complejo; terreno ya no monolítico sino campo de disputa; no ya el Estado como un altar que debe tomarse para su destrucción sino como un campo de inestabilidad, enfrentamiento, propenso y abierto a la posibilidad del reformismo. Para Poulantzas, el Estado es una necesidad organizativa necesaria para paliar las tensiones entre los distintos bloques dominantes. La tesis fundamental del alumno aventajado de Althusser, es que el Estado goza de una autonomía necesaria para poder asegurar la lógica del proyecto capitalista (frente a los intereses de los capitalistas individualistas que podrían ser contraproducentes para el mantenimiento del sistema mismo), llegando a ser de esta manera, en cierta medida, independiente a la clase dominante (ilustra esto con el ejemplo del bonapartismo tomado de Marx) (Poulantzas, 1971).

Claus Offe, a pesar de algunas diferencias con Poulantzas, considera que el Estado capitalista se va desarrollando en función de las crisis y de las contradicciones del sistema, intentado actuar como dispositivo equilibrador y garantista de la estructura de poder. Para ello, vive en una contradicción constante: por un lado simbólicamente garante del bien común (estrategia para garantizar el orden social) y por otro lado, y su principal tarea, servir a la acumulación capitalista (Offe, 1988). Estos autores, salvando sus distancias, se sirven de un Marx muy específico, o mejor dicho, de una lectura que les permite salvar en cierta medida al Estado y con ello a Marx: para poder concebir el Estado social en aquella época en la que se encuentran sus obras (años 70, 80), y que en teoría parecía ir en contra (el Estado del bienestar) de la tesis principal marxiana de desdeñar al Estado debido al ser el principal secuaz de la burguesía; pues este tipo de Estado nacido del constitucionalismo social de posguerra daba ciertas concesiones muy importantes a la clase obrera. Para ello buscan un Marx (Marx, 2009) en cierta medida gramsciano, que habría sabido comprender al Estado como un ente autónomo, como un campo de disputa y no como mero dispositivo instrumental del poder: esto es, de la clase burguesa.

También en tiempos recientes, continuando esta línea aunque de diferente manera, el último libro del difunto Giovanni Arrighi, siguiendo a Adam Smith en vez de a Marx, analizando la lógica mercantil en vez de la estatal, planteaba la posible existencia de economías de mercado no capitalistas ejemplificado en el caso del gigante chino, pues allí, supuestamente, 
el poder estatal se relacionaría con el mercado y no estaría el dispositivo estatal subordinado al interés de la clase capitalista; no existiría un mercado al servicio del capital (Arrighi, 2007). Aquí la confusión de Arrighi, creo, radica en no comprender que la clase dirigente china es capitalista, que la extracción de plusvalía sigue siendo fundamental, y que el Estado chino es un Estado capitalista, o para ser más exactos, que practica un capitalismo de Estado donde es el propio Estado en forma de gran capitalista el principal encargado de la valorización capitalista y no los capitalistas individuales, inversores particulares... funcionando de manera igual de eficaz el análisis marxiano.

Pero volviendo a las obras mencionadas de los años setenta y ochenta, desde nuestra concepción, estas perspectivas, a pesar de su ingenio, no son válidas; el Estado social no dejó de ser nunca un dispositivo al servicio del poder de mando. Lo único que la realidad material de aquel tiempo, exigía una lógica de dirigismo estatal en la economía, de aumento de los salarios, en definitiva, de Keynesianismo para poder salvar a la economía hegemónicamente productiva y fabril en esa época. La maquinaria estatal no es que sería un campo neutral de disputa, sino que en aquella época, nos encontrábamos ante un biopoder característico de las sociedades disciplinarias, que se escenificaba en el cuidado y disciplinamiento de la vida mediante la generalización y expansión de los servicios públicos característicos del Welfare state (Lazzarato, 2006: 83-85); la tarea del poder escenificada en el aparato estatal, era la de la gestión de la vida, una cuestión de pastoreo del rebaño en términos platónicos, o la gestión de la sociedad como un parque zoológico que necesita de sus cuidados si se prefiere la terminología reciente de Sloterdijk (Sloterdijk, 2008). El Estado social no es más que la forma Estado en era de la subsunción formal del trabajo en el capital (Hardt y Negri, 2003) ${ }^{10}$. Ahora, en la posmodernidad, en la era de la subsunción real, vemos claramente como la naturaleza estatal muta de un Estado benefactor a un Estado mínimo; esto no implica que el Estado tenga una voluntad más bondadosa o perversa que antes, sino que sencillamente el Estado ha mutado por las nuevas características que imponen las nuevas sociedades de control (Deleuze, 1995: 277 y ss.) y los intereses del capital: en este caso, un capital de corte financiero, donde la circulación prima sobre la producción, donde la finanza es cada vez más importante que la economía productiva.

\section{LA FORMA ESTADO DESDE LA ÓPTICA ALTHUSSERIANA Y FOUCAULTIANA}

De esta manera, después de haber expuesto muy sintéticamente y criticado muchas de las concepciones del Estado, se me dirá de qué estoy hablando exactamente cuando me refiero al Estado. En primer lugar, como intérpretes teóricos de Marx, sabemos que el Estado es un instrumento de la clase dominante. Esto es, en nuestra terminología, un dispositivo al servicio del dominio. Una concepción del Estado, leyendo a Althusser, que se ve como el dis-

${ }^{10}$ Para comprender las transformaciones del Estado en era de la subsunción formal del trabajo en el capital y en era de la subsunción real, véase la cita bibliográfica 
positivo central del que brotan los distintos aparatos que permiten producir la subjetividad de los individuos, y de esta manera, perpetuar la reproducción social adecuada para la empresa capitalista (Althusser, 2015). El Estado de esta manera, no es una simple institución más, no es un mero dispositivo coercitivo ni represivo, sino que tiene una función más importante, que es la de crear las condiciones de ordenación social para que todo funcione de acuerdo a las exigencias del poder. En este sentido, todo Estado sobrevive, más que por su capacidad de coerción, por su capacidad de dotarse de mecanismos de consentimiento; o en el sentido de Maquiavelo, no hay poder más efectivo que el que consigue presentarse como un no poder (Maquiavelo, 1944) (Maquiavelo, 1987) ${ }^{11}$. Eso es lo que pretende el Estado, ser un poder que parezca un no poder, y es lo que Althusser nos presenta a través de todos los AIE (aparatos ideológicos del estado) que tienen la función de crear esa apariencia de no poder del Estado.

Esta visión althusseriana enlaza, en cierta medida, con el materialismo genuino de Foucault. Para el pensador francés, el poder es una relación, una fuerza que se expande por todo el campo social mediante distintas relaciones de dominación que se encarnan en micropoderes. El poder no se podría poseer ni localizar en un lugar concreto; algo que dejaría muy tocado las tesis institucionalistas que consideran al Estado como ese lugar central desde donde se monopoliza el poder. De todas formas, esto no choca frontalmente con las tesis de Althusser, pues para él, el poder también es una relación fundante de las subjetividades: esto es la estructura de dominio denominada capital, que es una relación entre capital y trabajo, entre burguesía y proletariado, en definitiva, esa relación misma que es la lucha de clases. Sí es cierto que para Foucault esta relación no es primordial, pues las relaciones de poder son más microfísicas, más moleculares, insertas en el tejido social de manera intrínseca a la propia vida (recordemos que para Foucault la vida en su conjunto es objeto del poder: es decir estamos ante un biopoder), y por tanto, esa gran relación no es primordial.

Podemos decir que lo que para Foucault son dispositivos como la prisión, la escuela, la fábrica, y para Althusser aparatos, en los que se moldea la subjetividad de los sujetos, a pesar de coincidir en ambos la finalidad de tales dispositivos /aparatos, la diferencia radica en que para el marxista todos se reducen o pertenecen al Estado, mientras que para Foucault son exteriores. Es decir, a pesar de que para los dos el poder se encarna en aparatos-dispositivos, para uno pertenecen todos al Estado, mientras que para el otro están dispersos. Esto llevará a Deleuze a catalogar (desde nuestro punto de vista de manera exagerada) a Foucault de antialthusseriano:

Esto resulta anti-althusser, pues este afirma, repito, que incluso los aparatos, incluso, los poderes privados son aparatos especiales de Estado. Mientras que Foucault dice: incluso el aparato de Estado no hace más que gestionar los procedimientos del poder procedentes del exterior. Y aunque el aparato de Estado es el elemento constituyente

\footnotetext{
${ }^{11}$ La obra entera de Maquiavelo se podría definir en síntesis con esa frase. Tanto en el príncipe como en los discursos, el pensador florentino trata el poder desde una visión materialista, en la cual es consciente de la importancia suprema de las ficciones que rodean lo político, y que sin duda alguna, son las que definen este campo.
} 
de los grandes conjuntos, aunque el aparato de Estado, por definición, suponga relaciones de poder, no agota esas relaciones de poder, e implica relaciones de fuerzas procedentes del exterior. (Deleuze, 2014: 112-113)

Y Deleuze aún va más allá releyendo a Foucault:

Foucault nos da ejemplos muy concretos. Aquí dice: tomemos un engranaje del aparato de Estado como la policía (...) si algo parece pertenecer al Estado es la policía. Todos aquellos que definen el Estado como el monopolio de la fuerza lo entienden así. Foucault dice sí: pero no. Si se consideran de forma concreta las técnicas policiales se advierte que los procedimientos del poder policial son por naturaleza, sino siempre y constantemente, desde su origen, aplicados por el Estado, reutilizados por el Estado, pero el Estado en absoluto es su origen. La policía dispone de sus técnicas de poder, la policía dispone de sus procedimientos de poder (...) hay focos policiales que aparecen incluso en el espacio de comunidades sin aparato estatal (...) el Estado trata de apropiarse de los poderes policiales(...) el Estado se apropia de las disciplinas, no es el origen de las disciplinas. Las disciplinas escolares, las disciplinas militares, las disciplinas privadas... son siempre anteriores al Estado pero éste las recupera(...) en Vigilar y castigar (...) la cárcel no forma parte del horizonte del derecho penal, sino que es irreductible al poder jurídico, es relativamente independiente del poder jurídico, su poder procede de sí misma, es el poder de la cárcel. (Deleuze, 2014: 113-114) ${ }^{12}$

Sean del Estado o no, lo que está claro es que los dispositivos tienen la función de construir a los sujetos, de producir su imaginario colectivo, lo normal, lo correcto, que todo Estado irrumpa ante los ojos de la ciudadanía como un no poder, como un bien necesario, inimaginable su no existencia. Incluso, se puede alegar, que Foucault y Althusser, no eran lejanos en el tema del Estado, de hecho, quizás, se referían a lo mismo lo único que una cuestión meramente terminológica les separaba. Para Foucault, el Estado no era estrictamente más que la institución estatal, mientras que para Althusser no; el Estado era para éste todos los mecanismos del poder burgués, no solo una forma jurídica y administrativa, sino la dictadura burguesa, y esto era, todo lo que no era comunismo: es decir, todos los mecanismos que sujetan a los individuos y gracias a los cuales la reproducción del poder capitalista puede perpetuarse.

Hay algo en Althusser y Foucault que les une; y es una corriente de pensamiento, un tipo de metodología, materialista: el atender a las prácticas estatales para después establecer su definición, la edificación teórica; jamás basada en sentimentalismos, ni en esencialismos que perturben la definición del Estado. Foucault inició ese viaje metodológico, ese método para adentrarse en el estudio de la maquina estatal:

Partir de la práctica gubernamental es (...) dejar de lado como objeto primero, primitivo, ya dado, una serie de nociones como, por ejemplo, el soberano, la soberanía, el

\footnotetext{
${ }^{12}$ Deleuze, mostrándonos la independencia de los dispositivos en origen del aparato estatal, permite atisbar su propia teoría del Estado que no es otra que la del Estado como aparato de captura, es decir, un dispositivo que tiene la capacidad de reterritorializar todos los flujos que componen el mundo de la vida; por ello, siguiendo muy bien a Foucault, nos habla de que las disciplinas son siempre anteriores al Estado que éste más tarde incorpora.
} 
pueblo, los sujetos, el Estado, la sociedad civil: todos esos universales que el análisis sociológico, así como el análisis histórico y el análisis de la filosofía política, utilizan para explicar la practica gubernamental. (Foucault, 2012: 15)

Y continúa Foucault "Por mi parte me gustaría hacer justamente lo contrario, es decir partir de esa práctica tal como se presenta, para ver, sobre esa base como pueden constituirse en los hechos unas cuantas cosas sobre cuyo estatus habrá que interrogarse, por supuesto, y que son el Estado y la sociedad, el soberano y los súbditos, etcétera” (Foucault, 2012: 15). Esto no es un mero empirismo anglosajón sino un materialismo que no se lleva a engaños, analizando los mecanismos de producción de subjetividad, de obediencia, el estudio de la construcción de las distintas redes determinativas de los sujetos, algo que dista mucho de un simple análisis estadístico o cuantitativo.

\section{DELEUZE Y EL ESTADO COMO APARATO DE CAPTURA}

Si la forma Estado es un instrumento del poder capitalista (Marx), si además, tiene la capacidad de producir las subjetividades y se torna con demasiada frecuencia indestructible en la medida que se presenta como un no poder ante las masas (Foucault, Althusser, Maquiavelo...), Deleuze nos brindará la puntilla de esta concepción materialista del Estado al describirnos su lógica de funcionamiento, su discurrir por los senderos de la historia, sus objetivos, etc. Atendiendo a las prácticas estatales, siguiendo en cierta medida esta metodología materialista althusseriana y foucaultiana, Deleuze denominará a la forma Estado como aparato de captura. Para el filósofo francés, el Estado como aparato de captura, es un dispositivo que se encarga de recodificar los flujos que emiten las formas de vida; de reterritorializar las líneas de fuga del vivir. El Estado vive y se alimenta de las prácticas y formas de las multitudes deseantes. Esto le hace que sea secundario, que llegue tarde y vaya a contracorriente de los impulsos y desterritorializaciones de la multitud que intenta capturar.

La subjetividad espontanea del vivir, que se le escurre de las manos al poder como un jabón, tiene que ser sistemáticamente reabsorbida, mutando la naturaleza estatal. Esto, sin duda alguna, unirá a Deleuze con el pensamiento operario y autonomista italiano (Tronti, Negri...), donde son las luchas obreras las que determinan las transformaciones de la forma Estado y del sistema productivo (Tronti, 2001). Así, y a modo de ejemplo, si desde el pensamiento deleuziano mayo del 68 puede ser interpretado como una línea de fuga o una desterritorialización que acaba siendo subsumida por la reterritorialización o la captura del poder, del aparato de captura, en la medida que la cultura empresarial se ha basado desde el posfordismo en valores que surgieron en el 68 (Boltanski y Chiapello, 2002) a la vez que el Estado neoliberal se descentraliza y se diluye en la impronta también de esos mismos valores, de la misma manera el pensamiento operario italiano interpretará la contraofensiva neoliberal de los años 80, encarnada en Reagan y Tactcher, el posfordismo y la automatización, como una contrarrevolución del poder de mando que se servía de los mismos valores que acompañaron el ciclo de luchas que se abrió a finales de los 60 y principios de los 70. 
Pero volvamos más en concreto a la interpretación deleuziana del Estado como aparato de captura. Para Deleuze, el Estado poseería una naturaleza dual; tendría como dos polos: el del emperador terrible y mago (opera por captura, lazos, nudos y redes), y el del rey sacerdote y jurista (opera por pactos, tratados...). "El emperador mágico hace combatir a guerreros que no son los suyos, que pone a su servicio por captura (...) En cuanto al otro polo, el rey jurista es un gran organizador de la guerra; pero le da leyes, le prepara un campo, le inventa un derecho, le impone una disciplina, la subordina a fines políticos” (Deleuze y Guattari, 2012: 433-434) ${ }^{13}$. Ambos reyes coexisten, mientras que uno captura, seduce y conjura por hechizo, el otro opera un nuevo mundo para los hechizados. Mediante estas dos caras y otros elementos, el Estado se vuelve un receptor de los flujos de la vida que incorpora. Deleuze, de nuevo: "El Estado como aparato de captura tiene una potencia de apropiación; ahora bien esa potencia no solo consiste en que captura todo lo que puede, todo lo que le es posible, en una materia definida como filum. El aparato de captura se apropia igualmente de la máquina de guerra, de los instrumentos de polarización, de los mecanismos de anticipación conjuración.” (Deleuze y Guattari, 2012: 444). En definitiva, para Deleuze, el Estado no es más que un dispositivo que parasita la riqueza social, que es capaz de incorporar incluso las resistencias que se le oponen (“máquinas de guerra”).

Frente a lo que cree toda una mayoría de marxistas, generalmente la guardia ortodoxa, en Deleuze hay un espíritu de Marx, hay un instrumental marxiano para el análisis: ese capítulo dedicado en el Antiedipo a las formaciones precapitalistas, sin duda alguna, tiene un sabor dulce a los Grundrisse de Marx, o por no hablar de los análisis en mil mesetas sobre la violencia estatal que son ya descaradamente apologetas de Marx $^{14}$. Esa descripción de la violencia estatal, de rechazo del Estado, es absolutamente marxista (de Marx y solo de Marx, no de sus apologistas; es importante recordar esto). Sirviéndose de Marx, o mejor dicho, al igual que Marx, Deleuze trata de mostrar como la violencia del Estado trata de presentársenos como invisible, o como el Estado (retomemos a Maquiavelo) se presenta como un no poder:

Marx lo señala para el capitalismo: hay una violencia que pasa necesariamente por el Estado, que precede al modo de producción capitalista, que constituye la acumulación primitiva, y hace posible ese modo de producción. Si uno se sitúa en el modo de producción es difícil decir quién es el ladrón y quién es víctima, e incluso dónde está la violencia. Pues en él, el trabajador nace objetivamente desnudo y el capitalista vesti-

\footnotetext{
${ }^{13}$ Esta jerga deleuziana tan críptica, puede repeler a muchos. Sobre todo, a cierto marxismo que acusará a Deleuze y los suyos de "pensamiento débil”, de meros posmodernos... quizás, estas descalificaciones fuera de lugar, no se deban más que a sus prejuicios para intentar comprender un pensamiento que en lo barroco, poético y bello, es altamente riguroso y profundo. Frente a estas acusaciones también podemos encontrarnos excepciones, como en el caso de Frederic Jameson, que desde posiciones marxistas y hegelianas (fíjense que Deleuze era antidialéctico y antihegeliano) no tiene más remedio que reconocer la grandeza de Deleuze a pesar de sus diferencias: "la grandeza de Gilles Deleuze ( o al menos una de las muchas razones de su grandeza) consiste en haberse enfrentado omnívoramente al inmenso campo de todo lo que fue pensado y publicado. Nadie puede leer los dos volúmenes de Capitalismo y Esquizofrenia sin quedar anonadado ante el incesante flujo de referencias que incansablemente nutre estos textos, y que se procesan en un nuevo contenido y se organizan en dualismos” (Jameson, 2013: 210) ${ }^{14}$ Jameson lo atisba igual que nosotros: "Creo que Deleuze es el único entre los grandes pensadores del llamado posestructuralismo en haberle reconocido a Marx un rol absolutamente fundamental en su filosofía, en haber encontrado en el encuentro con Marx el acontecimiento más energizante de su obra tardía.” (Jameson, 2013: 211).
} 
do, propietario independiente. Lo que así ha formado trabajador y el capitalista se nos escapa, puesto que actúa en otros modos de producción. Es una violencia que se plantea como ya hecha, aunque se rehaga todos los días. (Deleuze y Guattari, 2012: 453)

Pero Deleuze, va más allá; de Marx y con Marx:

Ahora bien, esos análisis de Marx deben ser ampliados. Pues también hay una acumulación primitiva imperial que, lejos de derivar del modo de producción agrícola, le precede; por regla general, hay acumulación siempre que se organiza un aparato de captura, con esa violencia tan particular que crea o contribuye a crear aquello sobre lo que se ejerce, y que de esa forma se presupone. (Deleuze y Guattari, 2012: 453).

Allí, donde el Estado muta, donde el aparato de captura trata de absorber un flujo, hay acumulación de capital (pero no solo, de formas de vida, de subjetividad; aún hoy más, cuando el capital financiero, en era de la subsunción real, se sostiene en el mero vivir, en el trabajo inmaterial: cuidados, nuevas tecnologías, comunicación...), en aspectos cada vez más ligados a la vida en su conjunto: cuando la vida directamente es puesta a trabajar para la valorización capitalista, la acumulación es una empresa cotidiana, sustentada en los nuevos territorios vírgenes que imprime la misma innovación que es el vivir.

El Estado, de esta manera, se nos presenta como una cara de la explotación (la otra, el mercado; el capital al que el Estado sirve); pero sobre todo, es ese tramposo que se sabe inútil, y consigue engañarnos para parecer necesario:

La sobrecodificación de Estado es precisamente esa violencia estructural que define el derecho. Hay violencia de derecho siempre que la violencia contribuye a crear aquella sobre lo que se ejerce, o, como dice Marx, siempre que la captura ayude a crear lo que captura (...) el Estado puede entonces decir que la violencia es originaria, simple fenómeno de naturaleza, y que él no es responsable de ella, que él solo la ejerce contra los violentos, contra los “criminales”, contra los primitivos, contra los nómadas, para hacer que reine la paz... (Deleuze y Guattari, 2012: 454).

El Estado crea la violencia que le justifica; se legitima con los fantasmas que él mismo crea. Se apropia de la máquina de guerra, para demonizarla, y después, reprimirla; presentándose siempre como garante del orden y la paz social.

Sobre la modalidad de los distintos Estados, Deleuze nos habla de su "isomorfía”; es decir, que a pesar de sus diferencias, su función es la misma: la de la realización del capital en función de un solo y mismo mercado mundial. En rasgos generales distingue dos tipologías. Por un lado, un Estado multiplicador de axiomas (entendido esto como las distintas prestaciones sociales, el papel interventor en la economía, etc.; en definitiva, esta refiriéndose a un Estado complejo, al Welfare state), cuya naturaleza surge por la necesidad de organizar "un mercado interior integrado que compite con las exigencias del mercado exterior”. A este Estado, le denomina socialdemócrata, "por esa tendencia a la adjudicación, a la invención de axiomas, en relación con dominios de inversión y fuentes de beneficio: no es un problema de libertad o de coerción, de centralismo o descentralización, sino de cómo controlan los flujos...” (Deleuze y Guattari, 2012: 446). Por otro lado, habría una forma de Estado opuesta, caracterizada por la tendencia a retirar, a sustraer axiomas. 
El polo de Estado "totalitarismo" encarna esta tendencia a restringir el número de axiomas, y opera por promoción exclusiva del sector externo, recurso a los capitales extranjeros, desarrollo de una industria orientada hacia la exportación de materiales brutos o alimentarios, hundimiento del mercado interior. El Estado totalitario no es un máximo de Estado, sino más bien, según la fórmula de Virilio, el Estado mínimo del anarcocapitalismo (of.chile). En última instancia, los últimos axiomas retenidos son el equilibrio del sector externo, el nivel de las reservas, y la tasa de inflación. (Deleuze y Guattari, 2012: 467)

Deleuze no tiene piedad con el Estado: ni con la forma primera (hoy ya desaparecida o hacia esa tendencia, en la hegemonía del capitalismo financiero), ni con la forma segunda, en la que hoy en día vivimos, y que sin duda alguna, es resultado de la sustracción de axiomas en su terminología; privatizaciones y reducción del sector público en terminología común.

Lo que él atisbaba en ciertos países del tercer mundo o de América latina, y que algunos teóricos de la dependencia definieron como el extractivismo, hoy en día, se extiende por todo el mundo. Pero es que la magia de Deleuze es inagotable, y sus análisis no se detienen ahí. Cuando Toni Negri hablaba en el año 2000 (Hardt y Negri, 2005) de un primer mundo en el tercer mundo y de un tercer mundo en el primer mundo provocando el enfado de muchos representantes de marxismo clásico, no estaba sino siguiendo los análisis de Deleuze que ya anunciaba en 1980: "y los Estados del centro no solo tienen que enfrentarse al tercer mundo, no solo tienen cada uno un tercer mundo exterior, sino que también hay terceros mundos interiores que crecen en ellos y actúan sobre ellos desde dentro" (Deleuze y Guattari, 2012: 472). Para algunos esto resultará excesivo, sobre todo, para aquellos que sienten atacadas las teorías imperialistas de corte leninista.

Deleuze nos propone una cartografía para el siglo XXI, una lectura avanzada para su tiempo de la forma Estado actual, pero no solo, sino también, del mundo en el que vivimos. Ya lo dijo Foucault: “un día el siglo será deleuziano”. Y es que, la filosofía de Deleuze, con sus flujos constantes, con un capitalismo que captura esos mismos flujos, no es más que el análisis del capitalismo financiero actual; una ontología del ser en era posmoderna, del funcionamiento de la vida y del mundo de nuestra época.

\section{CONCLUSIONES}

Tras este breve desarrollo, podemos esgrimir a modo de conclusiones, desde el enfoque de estos autores, que la forma Estado se caracteriza desde la perspectiva althusseriana como el dispositivo central desde donde se ejerce el dominio y que la perspectiva foucaultiana, a pesar de parecer contraria a la de éste, puede ser ligada no sin dificultades con este enfoque materialista para abordar la definición estatal como dominación. Con Deleuze podemos enlazar la definición del Estado con su naturaleza, pues si el Estado se caracteriza fundamentalmente por atrapar los flujos, las líneas de fuga de las multitudes, éste se nos presenta como un dispositivo de constricción para las formas de vida. Estamos, por tanto, ante una naturaleza perversa para el fluir de la vida, y no, no juzgamos por una creencia esotérica 
y teológica, sino por un juicio asentado en un análisis material de las prácticas estatales, en ocasiones, escondidas bajo la apariencia de un no poder (Marx, Deleuze, Althusser... nos han servido para detectarlas). A pesar de todo, querríamos resaltar, que este rechazo a la forma Estado realmente existente no tiene porque entenderse como una negativa a la institucionalidad; de hecho, creemos en la necesidad para la vida de una forma de institucionalidad democrática que vaya más allá de las experiencias estatales en sus distintas vertientes (la forma Estado dictatorial, Estado del socialismo real, Estado mínimo neoliberal...) como de las derivadas del mercado, asentada en eso que últimamente se ha denominado como el común (Dardot y Laval, 2015). Pero eso ya, es otro asunto por abordar.

\section{BIBLIOGRAFÍA}

Althusser, L. (2015). Sobre la reproducción. Madrid: Akal.

Arrighi, G. (2007). Adam Smith en Pekín. Madrid: Akal.

Bobbio, N. (1977). El marxismo y el Estado. Barceloma: Avance.

Boltanski, L., y Chiapello, E. (2002). El nuevo espirtu del capitalismo. Madrid: Akal.

Dardot, P., y Laval, C. (2015). Común. Ensayo sobre la revolucion en el siglo XXI. Barcelona: Gedisa.

Deleuze, G. (1995). Post-scriptium sobre las sociedades de control. En Deleuze, G. (eds.), Conversaciones (1972-1990) (pp. 227 y ss.). Valencia: Pre-textos.

Deleuze, G. (2014). Michel Focault y el poder. Viajes iniciaticos. Madrid: Errata Naturae.

Deleuze, G., y Guattari, F. (2012). Mil mesetas. Capitalismo y esquizofrenia. Valencia: Pre-Textos.

Easton, D. (2013). Esquema para el analisis político. Buenos Aires: Amorrortu.

Foucault, M. (2012). Nacimiento de la biopolítica. Madrid: Akal.

Hall, J., e Ikenberry, G. J. (1993). El Estado. Madrid: Alianza.

Hardt, M., y Negri, A. (2003). El trabajo de Dionisos. Madrid: Akal.

Hardt, M., y Negri, A. (2005). Imperio. Barcelona: Paidós.

Jameson, F. (2013). Valencias de la dialéctica. Buenos Aires: Eterna Cadencia Editora.

Jellinek, G. (2012). Teoria general del Estado. Madrid: FCE-España.

Kelsen, H. (2008). Teoria general del Estado. Mexico: Cocoyal. 
Lazzarato, M. (2006). Por una política menor. Acontecimiento y política en las sociedades de control. Madrid: Traficantes de Sueños.

Maestro, G. (2001). Globalización y costitución débil. UNED-Teoría y Realidad Constitucional, $\mathrm{n}^{\circ}$ 7, primer semestre, pp. 137-172.

Maquiavelo, N. (1944). El principe. Escritos politicos. Madrid: Aguilar.

Maquiavelo, N. (1987). Discursos sobre la primera decada de Tito Livio. Madrid: Alianza.

Marx, K. (1971). Libro I capítulo VI inédito. Resultados del proceso inmediato de producción. México: Siglo XXI.

Marx, K. (2009). El 18 brumario de Luis Bonaaparte. Madrid: Alianza.

Mortati, C. (1969). Instituzioni di dirittto pubblico. Padova: Cedam.

Negri, A. (2001). Marx más allá de Marx. Madrid: Akal.

Negri, A. (2003). La forma-Estado. Madrid: Akal.

Offe, C. (1988). Contradicccines en el Estado del bienestar. México: Alianza.

Poulantzas, N. (1971). Poder Politico y Clases Sociales. México: Siglo XXI.

Poulantzas, N. (1979). Estado, Poder, y Socialismo. México: Siglo XXI.

Roldozski, R. (2004). Génesis y estructura de El Capital de Marx. México: Siglo XXI.

Sloterdijk, P. (2008). Normas para el parque humano. Madrid: Siruela.

Tronti, M. (2001). Obreros y capital. Madrid: Akal.

Weber, M. (1993). Economia y sociedad. Madrid: FCE-España. 